\title{
The medical management of hiatus hernia
}

\author{
Sir Francis Avery-Jones \\ C.B.E., M.D., F.R.C.P. \\ Central Middlesex Hospital, London
}

There is a changing pattern in outpatients at Central Middlesex these days and I wasn't too surprised when recently an attractive middle-aged rather overweight lady came along and said to me, 'Doctor, I have got a hiatus hernia. It doesn't trouble me very much except when I am invited up to dinner in the West End, and then I have a very bad night. I can go to dinner at other people's homes or locally and I seem to get away with it.' I went through exactly what happened when she went to a well-known and very good West End hotel. It was a special occasion so she dressed herself up and she had on a much tighter corset than usual. This was the first factor, as a tight corset increases intra-abdominal pressure and facilitates acid refluxing into the oesophagus, causing heartburn. Then she said, 'I take an extra pill before I go out. I take one of the Pro-Banthine tablets which the Doctor has given me.' As you have already heard from Dr Misiewicz, anti-cholinergic drugs are to be avoided when there is reflux, as they relax the lower oesophageal sphincter. So I said, 'Stop the tablet and I will give you another one which I think will help', and I gave her metoclopramide $10 \mathrm{mg}$ to take before she went out to dinner. I next asked what sort of chair she sat on at these occasions before dinner. This was a low chair in the lounge, but she chose a high chair at home. A low chair meant she might get hunched up, and this causes reflux and heartburn. Next, she said she smoked a cigarette, which she normally didn't do. Again, as you have heard, this stimulates the beta adrenergic system and relaxes the lower oesophageal sphincter. The meal she would have was much richer and more fatty, staying longer in the stomach and more likely to reflux during the night. As a result of her visit to outpatients and the re-arrangement of her evening programme, I am delighted to tell you that the last time she went to the West End for dinner she had no symptoms to worry her that night.

In treating a patient, the first point $I$ make is to show the X-rays and to explain what a hernia is, and a few minutes of explanation can save much trouble and worry for the patient subsequently. They have often got misconceived ideas and the word 'hernia' may be frightening. De-frighten the patient by getting rid of any misapprehensions and by giving a clear explanation, showing the importance of posture in preventing acid coming up into the oesophagus from the stomach. Using a simple diagram or the $\mathrm{X}$-ray, the time spent on explanation is time very well spent. Again, they are often worried about their heart, and this is particularly liable to happen if they get pain down the arm, as can occur in some cases of hiatus hernia. The pain of reflux comes on at rest, at night, or when sitting down in a low chair. They will ask if they can be cured and indeed many people are cured simply by weight loss. With an early case of sliding hiatus hernia the loss of $10 \mathrm{lb}$ is often enough to clear the patient of all symptoms of reflux. This is well worth stressing right at the onset, and explaining how they can set about losing weight. If they are sufficiently motivated from having sufficient symptoms there is never very much difficulty. Next, stress the importance of posturethe importance of not getting hunched up. A low chair is such a menace to these patients: a high chair, such as a wing chair, is splendid; a low chair particularly after a meal is to be avoided. In some of the modern cars, particularly the smaller ones, patients easily get hunched up and this may be quite enough to bring on their symptoms, even with a short journey. A small pillow behind their back is a real help. There is a regular stream of people from Heathrow Airport to Hillingdon Hospital sent there from the planes because they are suspected of having heart attacks. After having been hunched up on a long flight, they arrive at Heathrow with a lot of chest pain and they are sent to Hillingdon Hospital. Their posture on a long flight may have been quite enough to cause reflux and to simulate a heart attack.

The more patients burn their oesophagus with reflux, the more severe symptoms they have; the less they burn, the less symptoms; so care with posture is important. If they are picking something off the floor, they must bend at the knees and not at the hips. It is the same when doing up their shoes; they have got to bend the other knee-exactly the same as if they had a disc. The sleeping position is important, and getting propped up at night, particularly when symptoms have been acute, is most important. There are various ways of doing that: 
raising the head of the bed, or lowering the foot of the bed, and this is particularly advisable with associated disc trouble; two extra pillows may be enough for some people, but a useful technique is to have a foam wedge pillow at the head of the bed and another pillow can be pinned to it-very comfortable; a wedge pillow at the knees is also recommended.

Commonsense, smaller, less fatty and sweet meals are recommended for people with hiatus hernia. The osmotic pressure of sugar may cause much heartburn and discomfort. Coffee, which prolongs the acid secretion, is to be avoided. Of the antacids, Titralac is a good one because it dissolves instantly in the mouth. Smoking on general grounds should be avoided and it also has an inhibiting effect on the sphincter.

With nine out of ten patients with hiatus hernia simple measures along these lines keep their symptoms under good control; the tenth is unsuccessful, and here the surgeon comes in, and one may get tremendous help from him. 